\title{
Initiation of Antenatal Care and Number of Antenatal Visit among the Pregnant Women of Savar, Dhaka
}

\section{Shamima Nasrin Shadia ${ }^{1}$, Sadia Afrin ${ }^{2}$, Ken Yoshimura ${ }^{3}$ and Moazzem Hossain ${ }^{4 *}$}

1Lecturer, Department of Anatomy, GSVMC, Savar, Bangladesh.

2Medical Officer, Thalassemia Hospital and Institute, Savar, Bangladesh.

$3 \mathrm{MPH}$ Candidate, School of Tropical Medicine and Global Health, Nagasaki University Japan.

4Chairman, Institute of Allergy and Clinical Immunology of Bangladesh.

\begin{abstract}
Antenatal care (ANC) is a care given to pregnant women to timely identify and mitigate pregnancy related problems that can harm mother and/or fetus. Most of the Bangladeshi women present late for ANC. This study aims to determine the time of ANC initiation and the number of visit for ANC among pregnant women attending Filaria \& General Hospital between January 2016 and December 2018. The study population had adequate knowledge regarding ANC except for pregnant women who had visited minimum number for ANC. Among 1761 study population, 1268 (72\%) had registered for ANC, and 493(28\%) had not registered. Out of 1268, 651 (51.34\%) had their first ANC within the recommended time (before or at three months), and 617(48.66\%) started late initiation of their ANC care. Here, 649 (51.18\%) of the study population received more than three visits for ANC.
\end{abstract}

Corresponding author: Moazzem Hossain, Institute of Allergy and Clinical Immunology of Bangladesh, Zinzira, Savar, Dhaka, Bangladesh. Tel: 880- 1715038551; E-mail: moazzem.iacib@gmail.com

Received: December 03, 2019, Accepted: December 09, 2019, Published: December 13, 2019

Keywords: Antenatal Care, Pregnancy, Trimester, Bangladesh

\section{Introduction}

Antenatal care (ANC) is essential for the wellbeing of the mother and the child. All pregnant women are recommended to go for their first antenatal check-up in the first trimester to identify and manage any medical complication as well as to screen them for any risk factors that may affect the progress and outcome of their pregnancy [1].

This ANC should be provided by a medically trained provider to ensure the health of mother and fetus through early detection of risks in pregnancy, prevention of pregnancy and labor complications and ensures the safe delivery of mother and child to be most effec- tive and there should be regular ANC throughout pregnancy $[2,3]$.

Almost $90 \%$ of maternal deaths occur in developing countries where over half million women die each year due to pregnancy and childbirth related causes [4].

For example, Sub-Saharan Africa and Southern Asia accounted for approximately 86\% (254 000) of the estimated global maternal deaths in 2017. However, at the same time, between 2000 and 2017, Southern Asia achieved the greatest overall reduction in MMR: a decline of nearly $60 \%$ (from MMR of 384 down to 157). The high number of maternal deaths in some areas of the world reflects inequalities in access to quality health 
Citation: Moazzem Hossain (2019) Initiation of Antenatal Care and Number of Antenatal Visit among the Pregnant Women of Savar, Dhaka. Journal of Pathology Research Reviews \& Reports. SRC/JPR-104.

DOI: doi.org/10.47363/JPR/2019(1)104

services and highlights the gap between the rich and the poor. The MMR in low income countries in 2017 was 462 per 100000 live births versus 11 per 100000 live births in high income countries [5].

Studies demonstrating the high levels of maternal mortality in developing countries and research identifying causes of maternal death have repeatedly emphasized the need for prenatal care and the availability of trained personnel to attend to women during labor and delivery [6].

The use of ANC in developing countries is still low compared to developed countries (97\%) [7].

In developing countries, women often encounter serious health risks during pregnancy either for themselves (e.g., anemia, edema, and eclampsia) or for their children (e.g., sepsis and pneumonia, birth asphyxia and injuries, tetanus, congenital anomalies and with low birth weight) of the 210 million women who become pregnant each year, 30 million, or about $15 \%$, develop complications, which are fatal in $1.7 \%$ of cases [8].

The risk of maternal mortality and morbidity, as well as neonatal deaths can be reduced substantially through regular, proper ANC check-up and delivery under safe and hygienic conditions. In other words, a large majority of these deaths are preventable by providing ANC and assisting child birth via skilled birth attendants [9]. In Bangladesh, 64 percent of women who gave birth in the three years preceding the survey received antenatal care from a medically trained provider, up from 55 percent in 2011.This increase was mainly due to an increase in ANC from skilled birth attendants. Thirty-one percent of women have four or more antenatal care visit during pregnancy, an improvement from about one in every four (26 percent) in 2011 [3].

However, the number is still large.Available information suggests that about 12,000 women in Bangladesh die due to pregnancy-related complications10. Although proper ANC is one of the essential ways to reduce maternal and child morbidity and mortality, many women in developing countries including Bangladesh, do not receive such care [11]. Besides, considering WHO newest ANC guideline, which recommends that each woman attend eight of more routine ANC contacts between conception and birth, the percentage is to be even lower $[12,13,14]$.
Bangladesh has made a significant improvement towards achieving the Millennium Development Goal (MDG) target the 5 of $75 \%$ reduction in the MMR between 1990 and 2015 [15]. ANC is potentially one of the most effective health interventions for preventing maternal morbidity and mortality, particularly in places where the general health status of women is poor.

The present study highlights the time of initiation of ANC and number of ANC visit among the pregnant women in Savar, Dhaka.

\section{Methods}

This is a hospital based retrospective study on the antenatal women attending the outpatient department of Obstetrics and Gynae of Failaria \& General Hospital with study duration of three years (2016-2018). The study groups include all pregnant women attended in the department of obstetrics and Gynae in Filaria \& General Hospital. Descriptive statistics were used to compute percentage and average. The result was presented in a table and figures and expressed as percentage/proportion, mean and average.

\section{Result}

Figure1 shows that 1268 (72\%) out of 1761 pregnant women registered for ANC in this study. The re meaning 493 (28\%) had not registered for ANC. Out of those registered women for ANC, 51.34\% (651/1268) had registered in the 1st trimester followed by $31.39 \%$ $(398 / 1268)$ and $17.27 \%(219 / 1268)$ in the 3rd trimester and the 2nd trimester respectively. Hence 617 (48.66\%) women started late initiation of their ANC. Figure 2 shows that out of 1268 women, 651(51.34\%) had their first ANC within the recommended time (1st trimester). More than half 649 (51.18\%) of the study population received more than three antenatal visit and $619(48.82 \%)$ respondents received up-to three antenatal visit. Table. 1 shows that the majority of the mothers were $20-25$ years of age which $750(42.59 \%), 26-30$ years 466 (26.46\%), less than 20 years $290(16.47 \%)$ and more than 30 years 255 (14.48\%).

The reasons given by the individual women for not attending ANC were found to be the absence of illness (being healthy), being too busy, costly, poor quality of services and others. 
Citation: Moazzem Hossain (2019) Initiation of Antenatal Care and Number of Antenatal Visit among the Pregnant Women of Savar, Dhaka. Journal of Pathology Research Reviews \& Reports. SRC/JPR-104.

DOI: doi.org/10.47363/JPR/2019(1)104

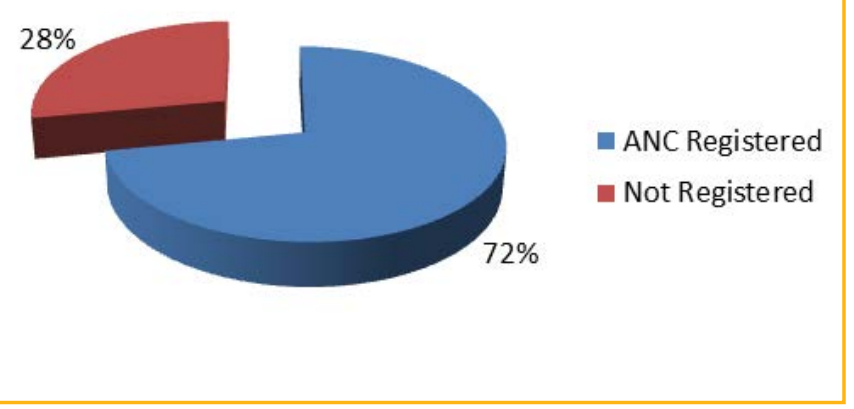

Figure 1: Distribution of study population according to their ANC registration status.

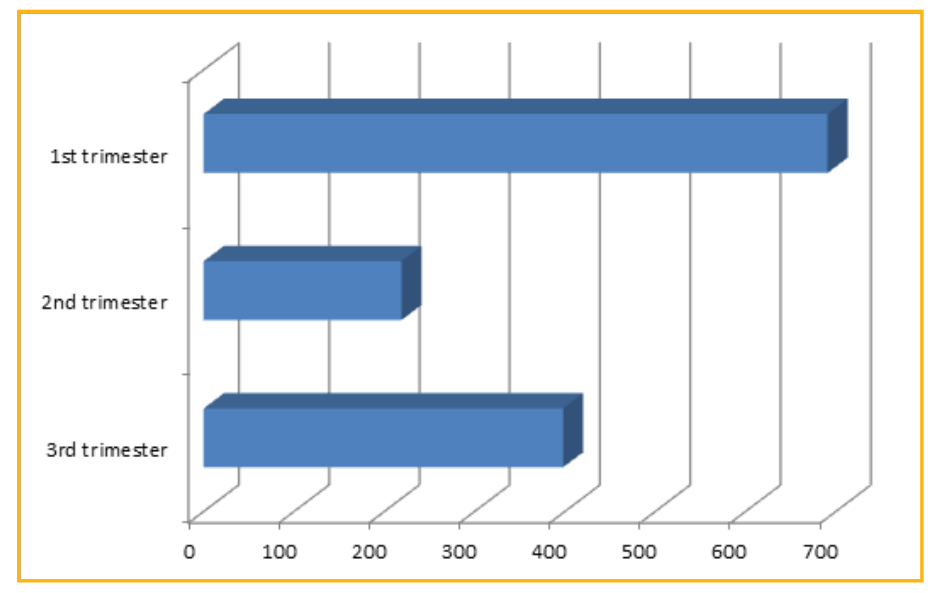

Figure 02: Distribution of registered population according

to their time of ANC.

\begin{tabular}{|l|l|l|}
\hline Age & Number & Percentage $(\%)$ \\
\hline$<20$ years & 290 & 16.47 \\
\hline $20-25$ years & 750 & 42.59 \\
\hline $26-30$ years & 466 & 26.46 \\
\hline$>30$ years & 255 & 14.48 \\
\hline Total & 1761 & 100 \\
\hline
\end{tabular}

Table-1: Distribution of study Population according to age.

\section{Discussion}

In the present study, nearly $70 \%$ of respondents belonged to the age group 20-30 years. In a study conducted by Rozliza et al., the majority of the respondents (46.2\%) were from the age group 20-29 year [16]. A Study conducted by Shirin $S$ et al., the mean age of women was

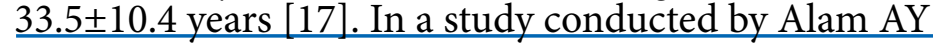

et al., the mean age of women was $29.57 \pm 7.1$ years [18]. This may be explained by the fact that mothers between this age group, their twenties have enough information on maternal healthcare services. A Similar study conducted by Manas Petal., most of the respondents were more than 25 years old [19].

Out of those registered for ANC, $51.34 \%(651 / 1268)$ had registered in the 1 st trimester followed by $31.39 \%(398 / 1268)$ and $17.27 \%(219 / 1268)$ in the 3rd trimester and the 2 nd trimester respectively among this respondents.

This results are in contrast to Javali who reported $56.5 \%$ and $42.9 \%$ women under ANC registration in the 1st trimester and the 2 nd trimester respectively, and Berhe who reported that $48 \%, 42.4 \%$, and $1.8 \%$ women made their first visit in the $1^{\text {st }}$ trimester, 2nd trimester and 3rd trimester respectively $[20,21]$. Also, higher rates of the tune of $63.9 \%$ were reported by Mumbare [22]. 1268 (72\%) out of 1761 pregnant women had registered for antenatal care, the remaining $493(28 \%)$ had not register for antenatal care in our study.

This result is higher than the result of Bangladesh Demographic and Health survey 2014 that 64 percent received ANC from a medically trained provider [3].

This is because the pregnant women who had registered for antenatal care were under our follow up and Filaria \& General Hospital places in the urban area as urban women are more likely than rural women to have more antenatal visits $[23,24]$.

\section{Conclusion}

It is assumed the most of our study's population had understood the importance of ANC since approximately $72 \%$ pregnant women had registered for ANC, and approximately half of them (51.34\%) had registered in the 1st trimester. Although the pattern of follow up was found to be in appropriate in most cases, our study's result was better than other result.

We need to emphasize that early registration should be utilized for the continuation of care and institutional delivery. If there was relatively high ANC utilization among the study population, but half of the mothers $617(48.66 \%)$ started utilizing ANC in their second and third trimester of pregnancy. Considering the late initiation of ANC visit of the study population, the effectiveness of the visit to reduce maternal morbidity and mortality could be hindered.

\section{Limitation}

Since this study was a retrospective descriptive study, we didn't analyze such as correlation between ANC visit and participant's background (salary, mediaexposure,place of residence). 
Citation: Moazzem Hossain (2019) Initiation of Antenatal Care and Number of Antenatal Visit among the Pregnant Women of Savar, Dhaka. Journal of Pathology Research Reviews \& Reports. SRC/JPR-104.

DOI: doi.org/10.47363/JPR/2019(1)104

\section{References}

1. AM Rosliza, HJ Muhamad (2011) "Knowledge, attitude and practice on ANC among orang asil women in JEMPOL, NEGERI SEMBILAN," Malaysian Journal of Public Health Medicine 11: 13-21.

2. SBabalola, A Fatusi (2009) "Determinants of use of maternal health services in Nigeria-looking beyond individual and household factors," BMC Pregnancy and Childbirth 9: 43.

3. BangladeshDemographic and Health Survey 2014.

4. Carroli G, Rooney C, Villar J (2001) How effective is antenatal care in preventing maternal mortality and serious morbidity? An overview of the evidence. Paediatric and Perinatal Epidemiology 15: 1-42.

5. World Health Organization Maternal mortality (2008) Fact sheet; Geneva. 2018. http://www.who.int/en/ newsroom/fact-sheets/detail/maternal-mortality last access date (November 9, 2019).

6. Rahman MM, Islam MR, Islam AZ (2008) Rural-Urban differentials of utilization of ante-natal healthcare services in Bangladesh 3: 117-125.

7. WHO (2007) Maternal mortality in 2005: Estimates developed by WHO, UNICEF, UNFPA and the World Bank. Geneva: World Health Organization 2007.

8. Rahman M, Islam R, and Rahman M (2010) Antenatal Care Seeking Behaviour among Slum Mothers a Study of Rajshahi City Corporation, Bangladesh. Sultan Qaboos Univ Med J 10: 50-56.

9. Khanal V, Brites Da Cruz JLN, Mishra SR, Karkee R, Lee AH (2015) Under-utilization of antenatal care services in Timor-Leste: results from Demographic and Health Survey 2009-2010. BMC Pregnancy and Childbirth [Internet] 15(1).

10. Saklain MA, Haque AE, Sarker MM (2011) Practice of 'Intra-natal Care and Characteristics of Mothers in a Rural Community. Dinajpur Med Col J 4: 71-76.

11. Ye Y, Yoshida Y, Harun-or-rashid M and Sakamoto J

(2010) Factors affecting the utilization of antenatal care services among women in Kham district, Xiengkhouang province. Lao Pdr. Nagoya J Med Sc 72: 23-33.

12. WHO (2016) Recommendations on antenatal care for a positive pregnancy experience 2016.

13.Tunçalp O, Pena-Rosas J, Lawrie T, Bucagu M, Oladapo O, Portela A, et al. (2017) WHO recommendations on antenatal care for a positive pregnancy experience-going beyond survival. BJOG: An International Journal of Obstetrics \& Gynecology 124: 860-862.

14. Siddique AB, Perkins J, Mazumder T, Haider MR, Banik G, Tahsina T, et al. (2018) Antenatal care in rural Bangladesh: Gaps in adequate coverage and content. PLOS ONE 13: e0205149.

15. Laishram J, Devi UT, Mukhia JPS, Devi HS (2013)
Knowledge and Practice of Ante-natal Care in an Urban Area. Indian Medical Gazette p 101.

16. Rozilza AM, Muhamad HJ (2011) Knowledge, Attitude and Practices on Antenatal care among women of Jempol, Negeri Sembilan, and Malaysian. J Public Health Med 11: 1321.

17. Shirin S (2011) Knowledge, attitude and practice of maternal health care amongst the married women in rural area of Bangladesh. Ibrahim Med Coll J 5: 13-16.

18. Alam AY, Qureshi AA, Adil MM, Ali H (2005) Comparative study of knowledge, attitude and practices among antenatal care facilities utilizing and non-utilizing women. J Pak Med Assoc 55: 53-56.

19. Roy MP, Mohan U, Singh SK, Singh VK, Srivastava AK (2013) Determinants of utilization of antenatal care services in rural Lucknow, India. Journal of family medicine and primary care 2: 55 .

20. Javali R, Wantamutte A, Mallapur MD (2014) Socio demographic factors inflencingutiizatin of antenatal health care services in a rural area A cross sectional study. Int J Med Sci Public Health 3: 308312.

21. Berhe KK, Welearegay HG, Abera GB, Kahsay HB, Kashay AB (2014) Assessment of antenatal care utilization and its associated factors among 15 to 49 years of age women in AyderKebelle, Mekelle City 2012/2013; a cross sectional study. Am J Adv Drug Deliv 2: 6275.

22. Mumbare SS, Rege R (2011) Antenatal care services utiizatin, delivery practices and factors affecting them in tribal areas of North Maharashtra. Indian J Community Med 36: 287290 .

23. Bangladesh Ministry of Health and Family Welfare Success Factors for Women's and Children's health https:// www.who.int/pmnch/knowledge/publications/bangladesh_ country_report.pdf last access date (November 9, 2019).

24. Rahman A, Nisha MK, Begum T, Ahmed S, Alam N, Anwar I (2017) Trends, determinants and inequities of 4+ ANC utilization in Bangladesh. Journal of Health, Population and Nutrition [Internet] 36(1). https://dx.doi.org/10.1186/ s41043-016-0078-5last access date (November 9, 2019).

Copyright: (c)2019 Moazzem Hossain.. This is an open-access article distributed under the terms of the Creative Commons Attribution License, which permits unrestricted use, distribution, and reproduction in any medium, provided the original author and source are credited. 